A Paper-Based Device for Colorimetric and Photoelectrochemical Quantification of the Flux of $\mathrm{H}_{2} \mathrm{O}_{2}$ Releasing from MCF-7 Cancer Cells

Li Li, ${ }^{a}$ Yan Zhang, ${ }^{a}$ Lina Zhang, ${ }^{\mathrm{b}}$ Shenguang Ge, ${ }^{\mathrm{a}, \mathrm{b}}$ Haiyun Liu, ${ }^{\mathrm{a}} \mathrm{Na}$ Ren, ${ }^{\mathrm{c}}$ Mei Yan, ${ }^{\mathrm{a}}$ and Jinghua $\mathrm{Yu}^{* \mathrm{a}}$

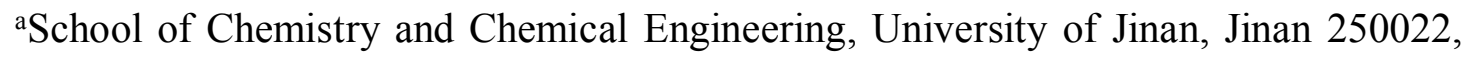
P.R. China.

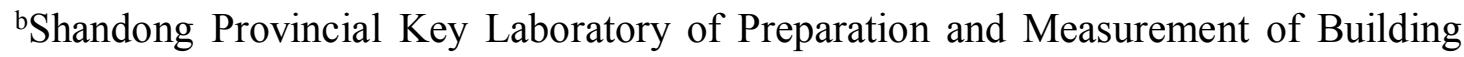
Materials, School of Material Science and Engineering, University of Jinan, Jinan 250022, P.R. China.

${ }^{\mathrm{c} S c h o o l ~ o f ~ B i o l o g i c a l ~ S c i e n c e ~ a n d ~ T e c h n o l o g y, ~ U n i v e r s i t y ~ o f ~ J i n a n, ~ J i n a n ~ 250022, ~ P . R . ~}$ China. 


\section{Cell culture}

MCF-7 (human breast carcinoma) cells were cultured in dulbecco's modified eagle medium (DMEM) supplemented with $10 \%$ fetal bovine serum and $1 \%$ penicillin/streptomycin. Cultures were maintained at $37{ }^{\circ} \mathrm{C}$ and in $5 \% \quad \mathrm{CO}_{2}$ atmosphere. The culture medium was changed every other day and the cells were passaged when they reached $80-90 \%$ confluency. When cultured for two days, tumor cells were digested by pancreatic enzymes and dispersed in PBS. After being blown well, tumor cells were counted by a Petroff-Hausser cell counter (U.S.A.).

The aptamer used in this study was purchased from Sangon Biotechnology Co., Ltd. (Shanghai, China), and the sequences of oligonucleotides were given as follows: Aptamer for functionalization FL-Au@Pd alloy NPs: 5'-NH2-AAAGAAAGAA AGAAAGAAAG-SH-3'

\section{Apparatus}

Ultraviolet-visible (UV-vis) absorption spectra were recorded on a UV-2550 spectrophotometer (Shimadzu, Japan). Scanning electron microscopy (SEM) images were obtained using a QUANTA FEG 250 thermal field emission scanning electron microscope (FEI Co., USA). Transmission electron microscopy (TEM) images were obtained from a JEOL JEM-1400 microscope (Japan). Electrochemical impedance spectroscopy (EIS) was performed on an IM6x electrochemical station (Zahner, Germany). X-ray photoelectron spectroscopy (XPS) was carried out on an ESCALAB MK II X-ray photoelectron spectrometer. The phase characterization was performed by X-ray diffraction (XRD) using a D8 advance diffractometer system equipped with $\mathrm{Cu}$ Ka radiation (Bruker Co., Germany). 


\section{Electrophoresis analysis}

For performance of the gel electrophoresis, aliquots of $10 \mu \mathrm{L}$ of each sample containing $15 \%$ glycerol were loaded onto a $3 \%$ agarose gel and electrophoresed at $100 \mathrm{~V}$ for $60 \mathrm{~min}$ at room temperature. The photograph was taken by BIO-RAD Molecular Imager.

\section{Fabrication and characterization of the Paper-Based device}

The 3D $\mu-\mathrm{PEC} / \mathrm{C}$ was fabricated using a previously reported method $^{1}$ and a detailed procedure was described below. A wax-printing technique was used to create this $3 \mathrm{D} \mu-\mathrm{PEC} / \mathrm{C}$ because this fabrication process is simpler, less expensive, and faster than other reported methods. ${ }^{2,3}$ Adobe illustrator CS4 software was used to create the device design. The wax-pattern was printed onto Whatman chromatography paper \#1 using a commercially available solid-wax printer (FUJIXEROX Phaser 8560DN, Japan) (Figure S1). This origami device was comprised of a channel tab $(17.0 \mathrm{~mm} \times$ $20.0 \mathrm{~mm})$, one detection tab and one reference tab $(17.0 \mathrm{~mm} \times 20.0 \mathrm{~mm})$. After the wax-printed paper sheet was baked in an oven at $130{ }^{\circ} \mathrm{C}$ for $150 \mathrm{~s}$, the printed wax melt and penetrate through the paper to form the hydrophobic and insulating patterns (Figure S2). Then, the wax-penetrated paper sheet was ready for screen-printing of electrode. The unprinted hydrophilic area on the detection tab, containing one PEC working zone $(6.0 \mathrm{~mm}$ in diameter) for screen-printed carbon working electrode (Figure S3), one pretreatment zone $(3.0 \mathrm{~mm}$ in diameter) and one colorimetric detection zone ( $4.0 \mathrm{~mm}$ in diameter) to achieve chromogenic reactions. The other pretreatment zone $(3.0 \mathrm{~mm}$ in diameter) and colorimetric detection zone $(4.0 \mathrm{~mm}$ in diameter) was used as an evidence that the chromogenic reactions went through a radical chain mechanism. ${ }^{4}$ The unprinted hydrophilic area on the reference tab $(8.0$ $\mathrm{mm}$ in diameter) was used for screen-printed $\mathrm{Ag} / \mathrm{AgCl}$ reference electrode and carbon 
counter electrode (Figure S4). Via hole on the reference tab was covered by an $\mathrm{Au}$ NPs layer to make both side of the sample tab conductive, which was sealed by silver on the reverse side of reference tab (Figure S4). Finally, the paper sheet was cut into individual origami paper-based analytical device for further modifications. After folding at the predefined fold line (1 $\mathrm{mm}$ in width), the three screen-printed electrodes would be connected once the paper cell was filled with solution. 


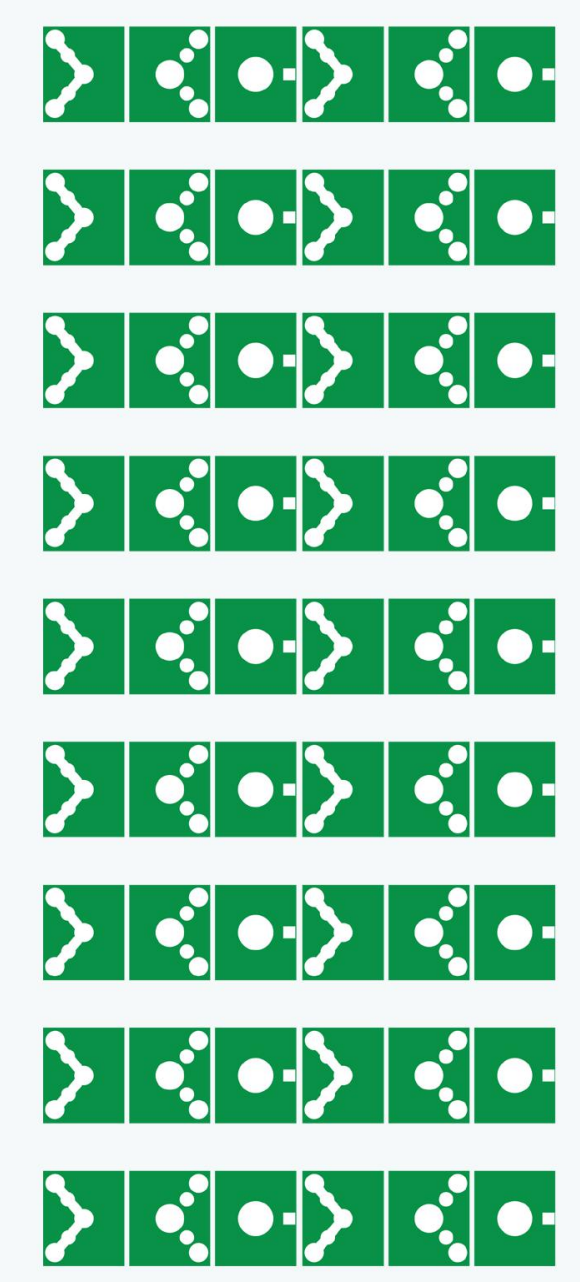

1

2 Figure S1. Wax-patterns of the 3D $\mu-\mathrm{PEC} / \mathrm{C}$ on a paper sheet (A4) before baking. 3 

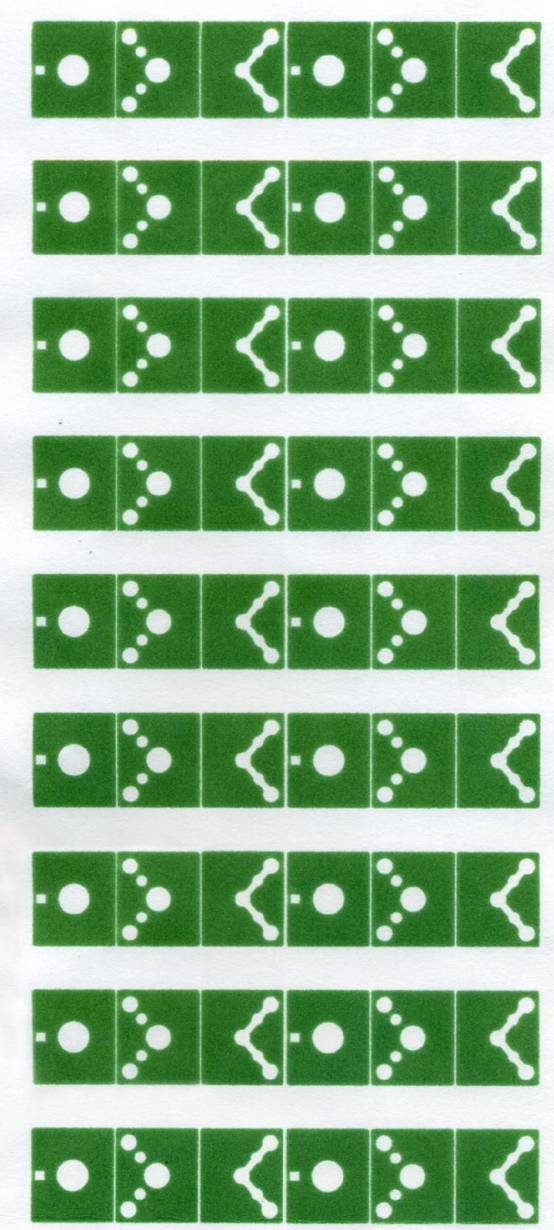

Figure S2. Wax-patterns of the 3D $\mu-\mathrm{PEC} / \mathrm{C}$ on a paper sheet (A4) after baking. 6 

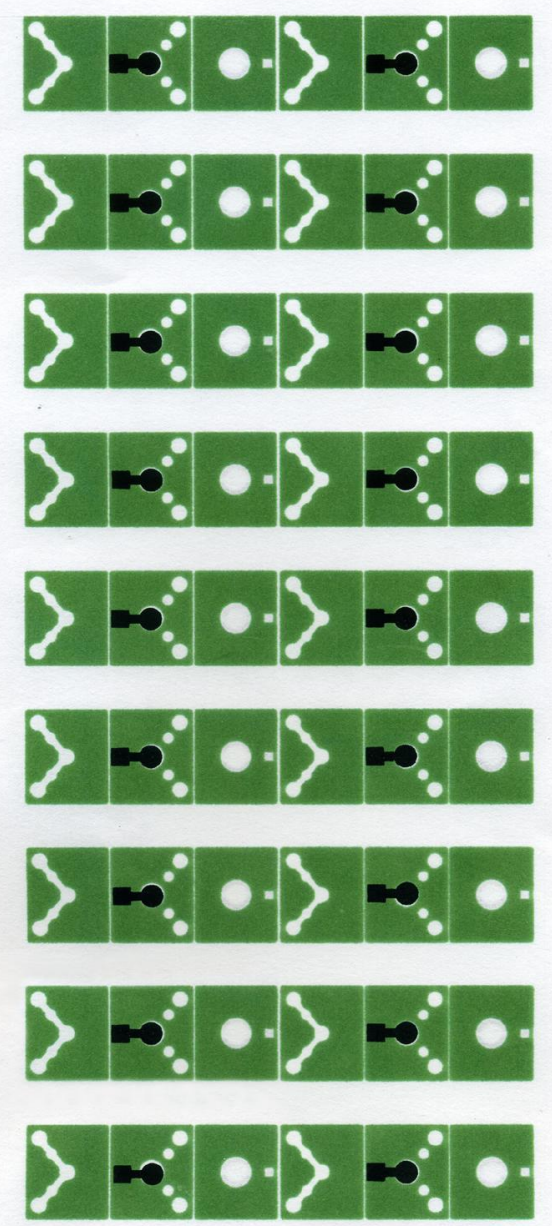

Figure S3. The 3D $\mu$-PEC/C on a paper sheet (A4) after screen-printing working electrodes. 


\section{$8: 28: 0$}
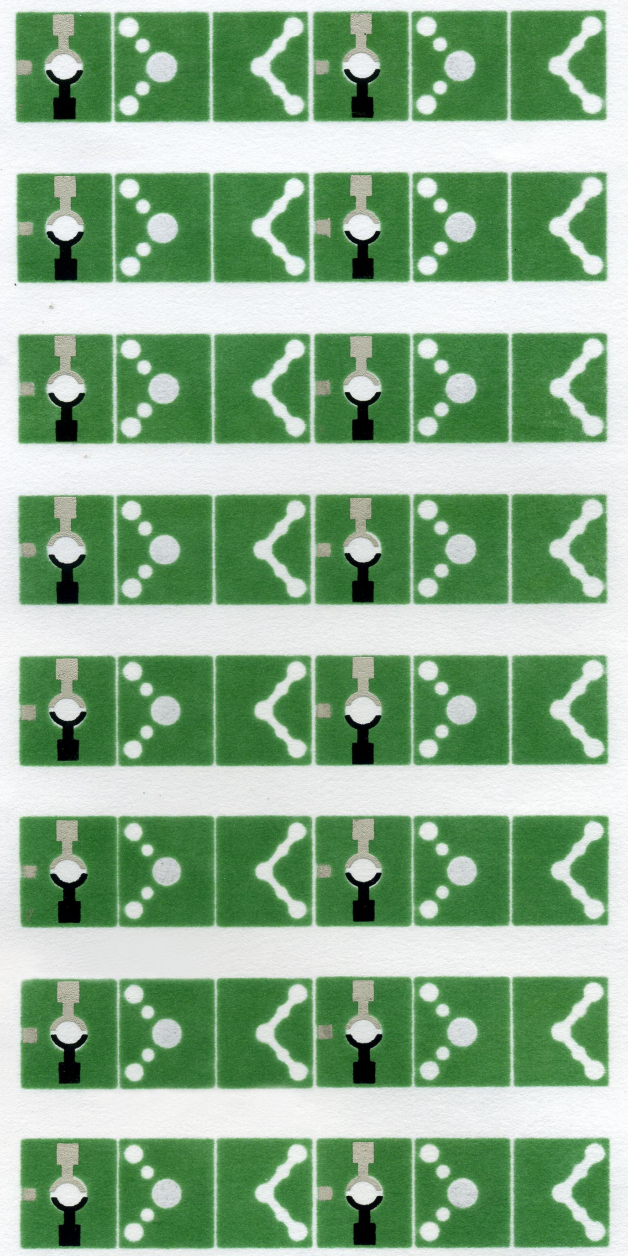

Figure S4. Reverse side of the 3D $\mu-\mathrm{PEC} / \mathrm{C}$ on a paper sheet (A4) after screen-printing reference electrodes and counter electrodes. 


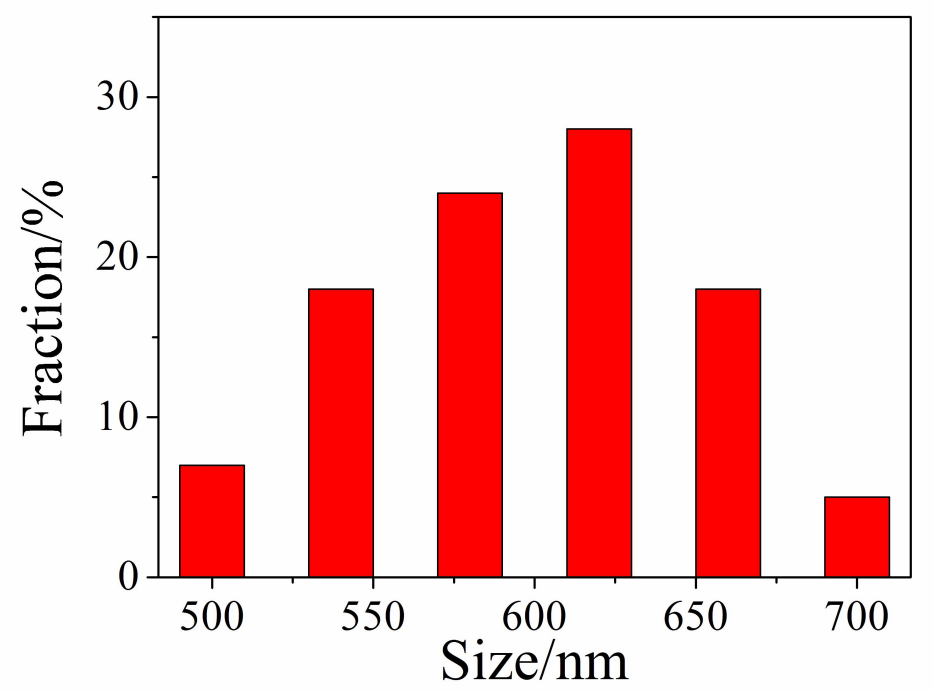

Figure S5. Size distributions of FL-Au@Pd NPs.

\section{Characterization of the 3D $\mu-\mathrm{PEC} / \mathrm{C}$ device}

$\mathrm{CV}$, an effective tool for the investigation of self-assembled monolayers on the electrode surface, was employed to characterize the fabrication process of the $\mathrm{PEC} / \mathrm{C}$ cyto-sensor at different stages with the sensitive redox couple of $\left[\mathrm{Fe}(\mathrm{CN})_{6}\right]^{3-/ 4-}$ in $\mathrm{KCl}$ solution $(0.1 \mathrm{M})$. As shown in Figure S6A, the bare PWE exhibited a well-defined redox peak of $\left[\mathrm{Fe}(\mathrm{CN})_{6}\right]^{3-/ 4-}($ curve a). When the Pt NPs were grown on the PWE surface, the peak current apparently increased (curve b), because the conductive Pt NPs could accelerate the electron transfer. Subsequently, the CV response decrease sequentially (curves c-f) when BL-ZnO, Con-A, GQDs/Apt/FL-Au@Pd (referred to as probe agents) and cells were introduced on the surface of the Pt-PWE, testifying that the assembly of different substances inhibited the transmission of electrons. 
(Figure S6B). Compared with the impedance spectrum of bare PWE (curve a), after the Pt NPs were grown onto PWE, the electron-transfer resistance $\left(R_{\mathrm{et}}\right)$ decreased significantly (curve b). These results were accordant with CV assays as described in detail above. After BL-ZnO NPs were grown onto the surface of Pt-PWE, an increase in $R_{\text {et }}$ value was observed (curve c). Subsequently, Con-A and GQDs/Apt/FL-Au@Pd were constructed on the BL-ZnO/Pt-PWE step by step, and the $R_{\text {et }}$ of each related PWE increased correspondingly (curves d-e). After cells was added, the $R_{\text {et }}$ augmented gradually on account of the steric hindrance (curve f), indicating the successful immobilization of cells via the specific binding between the immobilized Con-A and cells. The stepwise increase of electron transfer resistance verified the successful fabrication of the PEC cyto-sensor.
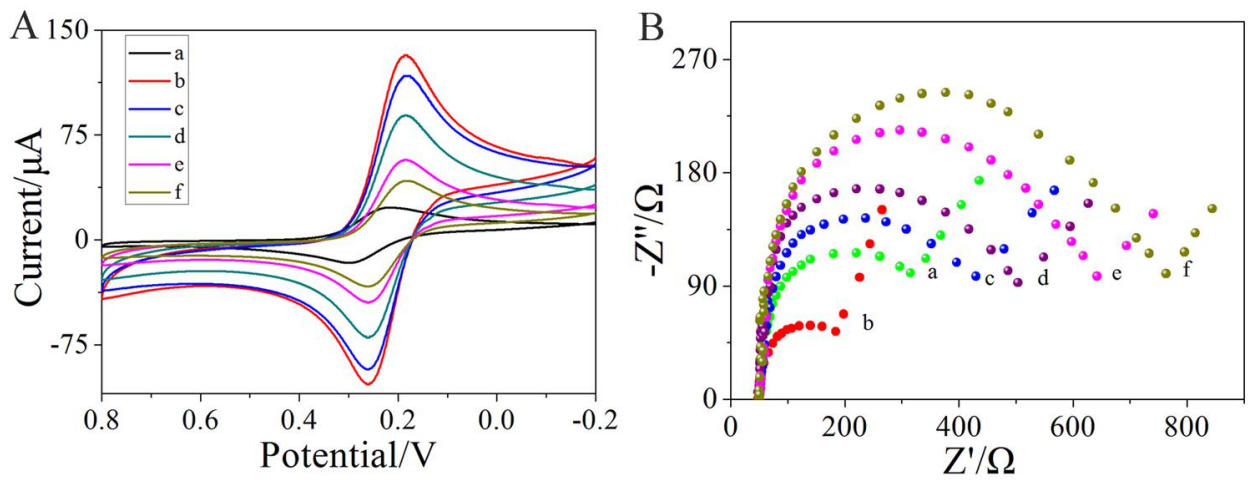

Figure S6. CV (A) and EIS (B) of bare PWE (a); Pt-PWE (b); ZnO modified Pt-PWE (c); Con-A modified ZnO/Pt-PWE (d); GQDs/Apt/FL-Au@Pd modified Con-A/ZnO/Pt-PWE (e) and cells modified GQDs/Apt/FL-Au@Pd/Con-A/ZnO/Pt-PWE (f) in $0.01 \mathrm{M}$ PBS (2.5 mM $\left[\mathrm{Fe}(\mathrm{CN})_{6}\right]^{3-/ 4-}$ containing $0.1 \mathrm{M} \mathrm{KCl}, \mathrm{pH} 7.4$ ).

\section{Optimization of colorimetric experimental conditions}

To obtain the optimal colorimetric analytical performance, the effects of $\mathrm{pH}$, temperature and thiourea aqueous concentrations and cleavage time of DNA by $\mathrm{OH}$ 
were investigated, respectively. As can be seen, an optimal catalytic activity of the GQDs/Apt/FL-Au@Pd was obtained at pH 4.6. A higher or lower pH resulted in the decrease of catalytic activity (Figure S7A). Therefore, HAc-NaAc buffer ( $\mathrm{pH} 4.6)$ was selected for following colorimetric measurements.
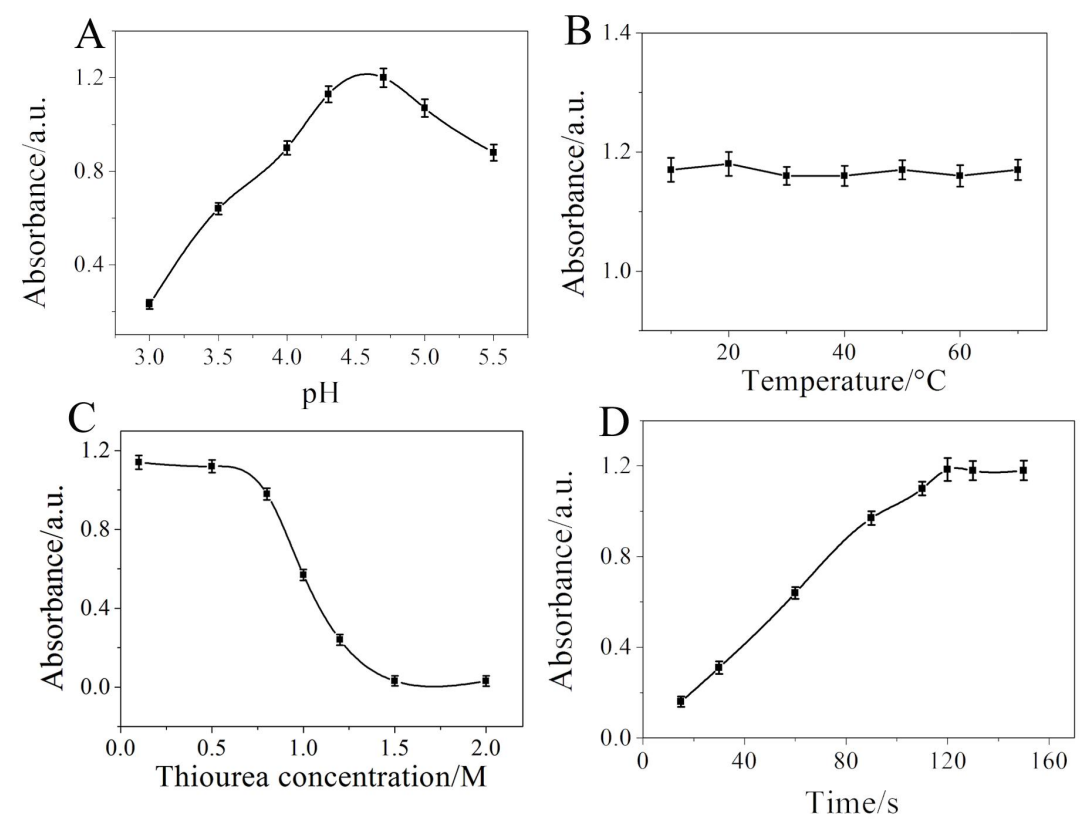

Figure S7. (A) Effect of the pH; (B) Temperature; (C) Thiourea concentration; (D) Cleavage time of DNA by $\cdot \mathrm{OH}$

The temperature played important roles in our colorimetric measurements. As shown in Figure S7B, the characteristic absorbance of the oxidized product changed slightly with increasing temperature, indicating super long-term stability of the hybrid particles. For convenient testing, we chose room temperature as reaction temperature.

To evidence it was $\cdot \mathrm{OH}$ which is catalyzed by the GQDs/Apt/FL-Au@Pd that react with $\mathrm{TMB}$ to form a blue color product. Different concentration of thiourea, a typical $\cdot \mathrm{OH}$-scavenger, was added into the pretreatment zone to terminate the colorimetric reaction. In the examined concentration range, the minimum UV 
absorption responses occurred when concentration of thiourea was close to $1.5 \mathrm{M}$ (Figure $\mathrm{S} 7 \mathrm{C}$ ). Therefore, $1.5 \mathrm{M}$ thiourea was selected as the optimal concentration.

The cleavage time of DNA by $\cdot \mathrm{OH}$ was a significant parameter for the extent that the fracture of DNA strand and colorimetric responds. With incubation time increased, the colorimetric responses intensity for TMB increased gradually and reached a plateau after $2 \mathrm{~min}$ (Figure S7D), indicating a tendency to complete breakage of DNA. Thus, 2 min was used as the optimal chain interruption time.

\section{Optimization of the PEC assay conditions}

To achieve excellent PEC performance in a sensitive assay of DNA, several experimental parameters, such as PMA concentration and stimuli varieties were investigated (Figure S8). As shown in Figure S8A, a decrease of PEC intensity was observed with the PMA concentration range from $10-200 \mathrm{ng} \cdot \mathrm{mL}^{-1}$, indicating the flux of $\mathrm{H}_{2} \mathrm{O}_{2}$ released from the cells significantly increases with enhancement of the PMA concentration, showing a PMA concentration-dependent manner. The stimuli could stimulate the tumor cells to release $\mathrm{H}_{2} \mathrm{O}_{2}$, and finally decrease the photocurrent. Thus, the optimal stimuli of cells could play a significant role in optimizing the photocurrent signal, which could be estimated by the photocurrent with different stimuli, such as PMA, ADP, and fMLP, which were reported to induce the generation of $\mathrm{H}_{2} \mathrm{O}_{2}$ in cells. ${ }^{5}$ As shown in Figure S8B, the PEC signals decreases in the order ADP, fMLP, and PMA (each at a concentration of $200 \mathrm{ng} \cdot \mathrm{mL}^{-1}$ ), indicative of a stimulus type-dependent manner. 

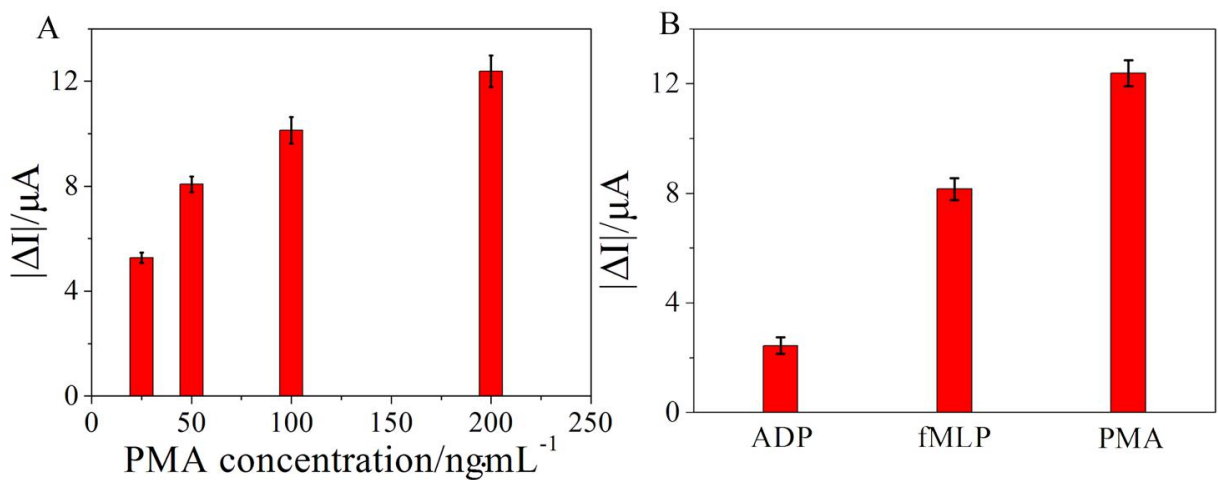

Figure S8. (A) Dependence of the flux of $\mathrm{H}_{2} \mathrm{O}_{2}$ released from the cells on the concentration of PMA; (B) The flux of $\mathrm{H}_{2} \mathrm{O}_{2}$ released from the cells induced by $200 \mathrm{ng} \cdot \mathrm{mL}^{-1}$ ADP, fMLP, and PMA, respectively.

\section{Detection of $\mathrm{H}_{2} \mathrm{O}_{2}$ standard solution at our tumor cell immobilized $\mathrm{ZnO} / \mathrm{Pt}-\mathrm{PWE}$}

To demonstrate the sensitivity of our developed detection method for monitoring the release process and measuring the flux of $\mathrm{H}_{2} \mathrm{O}_{2}$ from cells, $\mathrm{ZnO} / \mathrm{Pt}-\mathrm{PWE}$ was
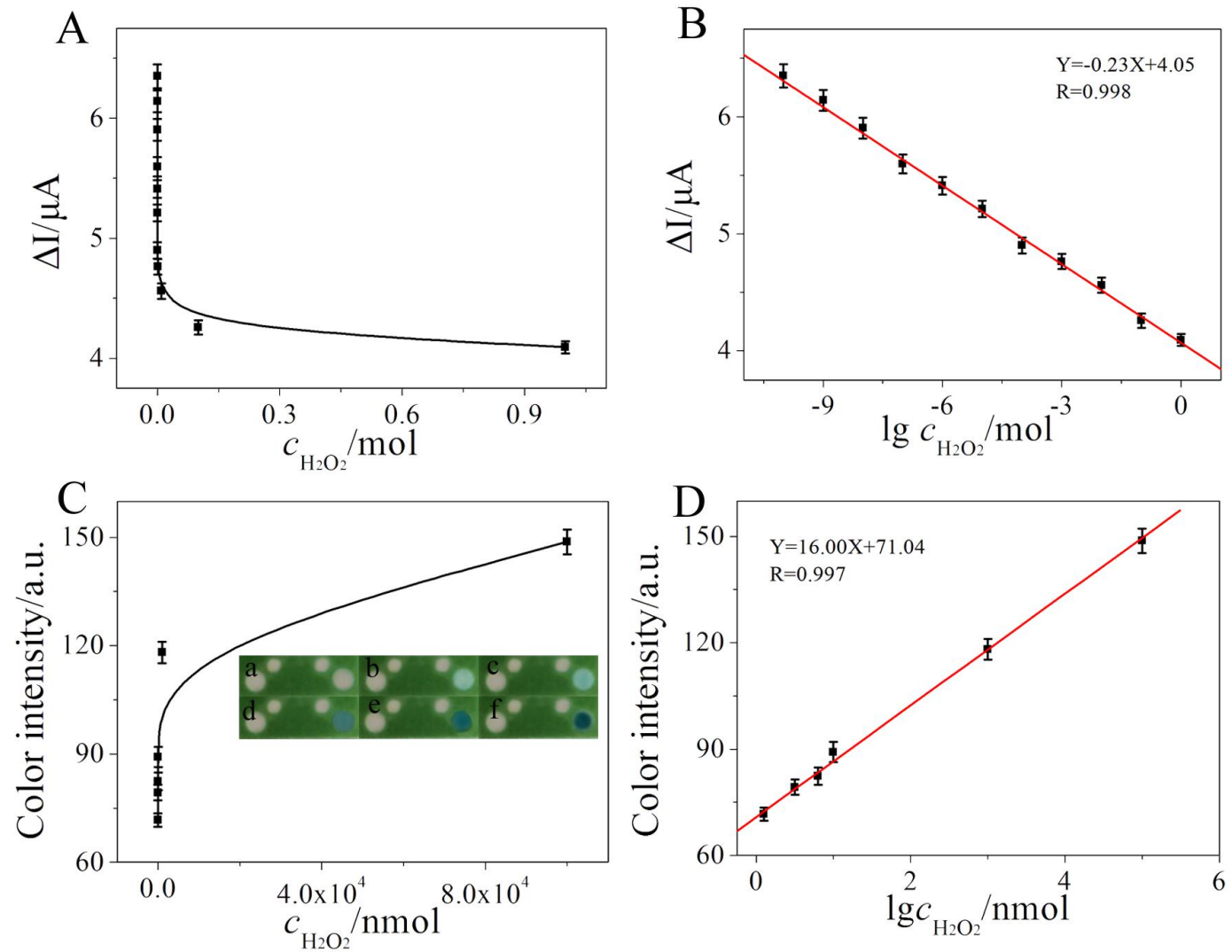

Figure S9. The $\operatorname{PEC}(\mathrm{A}, \mathrm{B})$ and grey responses $(\mathrm{C}, \mathrm{D})$ of the tumor cells immobilized $\mathrm{ZnO} / \mathrm{Pt}-\mathrm{PWE}$ towards various concentrations of $\mathrm{H}_{2} \mathrm{O}_{2}$ (A,C); calibration curve for $\mathrm{H}_{2} \mathrm{O}_{2}$ determination (B,D). Inset: colorimetric imaging of the $\mu-\mathrm{PEC} / \mathrm{C}$ incubated with different concentrations of $\mathrm{H}_{2} \mathrm{O}_{2}$, a to f: 1.3, 3.2, 6.3, 10, 1000, 100000 nmol, respectively. 
treated with $\mathrm{H}_{2} \mathrm{O}_{2}$ under a series of different concentrations to obtain the standard curves of PEC/grey intensity versus $\mathrm{H}_{2} \mathrm{O}_{2}$ concentration (early determined using a standard $\mathrm{KMnO}_{4}$ solution). The obtained results were shown in Fig. S9.

Table S1 The results of comparing with other detection methods.

\begin{tabular}{cccc}
\hline Detection methods & Linear range $(\mu \mathrm{M})$ & Detection limit $(\mu \mathrm{M})$ & Ref. \\
\hline Colorimetric methods & $0.02-5 \times 10^{4}$ & 0.0086 & 6 \\
Colorimetric methods & $0.1-100$ & 0.033 & 7 \\
Colorimetric methods & $0.0013-100$ & 0.0013 & This work \\
Photoelectrochemical methods & $10-60$ & 2.2 & 8 \\
Electrochemical methods & $10^{-4}-10^{3}$ & - & 9 \\
Photoelectrochemical methods & $10^{-4}-10^{6}$ & $5 \times 10^{-5}$ & This work \\
\hline
\end{tabular}

\section{Corresponding Author}

*E-mail: ujn.yujh@gmail.com. Phone: +86-531-82767161.

\section{References}

(1) Ge, L.; Yan, J. X.; Song, X. R.; Yan, M.; Ge, S. G.; Yu, J. H. Biomaterials 2012, 33, 1024.

(2) Lu, Y.; Shi, W. W.; Jiang, L.; Qin, J. H.; Lin, B. C. Electrophoresis 2009, 30, 1497.

(3) Carrilho, E.; Martinez, A. W.; Whitesides, G. M. Anal. Chem. 2009, 81, 7091.

(4) Kitajima, N.; Fukuzumi, S.; Ono, Y. J. Phys. Chem. 1978, 82, 1505.

(5) He, W. F.; Liu, G.; Chen, X.; Lu, J. C.; Abe, H.; Huang, K. X. J. Agric. Food Chem. 2008, 56, 1921.

(6) Ge, S. G.; Liu, W. Y.; Liu, H. Y.; Liu, F.; Yu, J. H.; Yan, M.; Huang, J. D. Biosens Bioelectron. 2015, 71, 456-462.

(7) Chen, S.; Hai, X.; Chen, X. W.; Wang, J. H. Anal. Chem. 2014, 86, 6689-6694.

(8) Li, H. X.; Hao, W. L.; Hu, J. C.; Wu, H. Y. Biosens. Bioelectron. 2013, 47, 225-230.

(9) Liu, F.; Ge, S. G.; Yu, J. H.; Yan, M.; Song, X. R. Chem. Commun., 2014, 50, 10315-10318. 